\title{
Improved Langley and Ratio Langley Methods for Improving Sky-Radiometer Accuracy
}

\author{
Kohei Arai \\ Dept. of Information Science \\ Saga University \\ Saga City, Japan
}

\begin{abstract}
Improved Langley Method (ILM) is proposed to improve the calibration accuracy of the sky-radiometer. The ILM uses that the calibration coefficients of other arbitrary wavelengths can be presumed from the calibration coefficients in a certain reference wave length, and improves the calibration accuracy of a full wave length region by Ratio Langley Method (RLM) in long wavelength paying attention to calibration accuracy being good comparatively was proposed. Specifically, the calibration coefficient of other wavelengths was presumed by the RLM from the calibration factor by ILM in 0.87 micrometer. The numerical simulation based on measured data of solar direct and aureole when the calibration error of the proposed method was evaluated about the case where $\pm 3 \%$ and $\pm 5 \%$ of measurement error is superimposed on the measurement data solar direct and aureole, the maximum with error was 0.0014 and 0.0428 , and they of ILM were 0.011 and 0.0489 . Therefore, the proposed calibration method is robust for a measurement error compared with ILM, and was understood that highly precise calibration is possible over full wavelength. When the standard deviation of a calibration coefficients estimated the accuracy of the proposed calibration method based on the measured data of the sky-radiometer for 15 days which fits calibration among the measured data for four years or more, it was 0.02016 , and since it was smaller than the standard deviation $\mathbf{0 . 0 3 8 5 8}$ of the calibration coefficients by ILM, the predominance of the proposed calibration method has been confirmed.
\end{abstract}

Keywords-Calibration; Langley plot; improved Langley method; ratio Langley method; aerosol optical depth; volume spectrum

\section{INTRODUCTION}

Attempts have been made to estimate the aerosol complex refractive index and particle size distribution using the downward radiance on the ground obtained by a radiometer (sky-radiometer) that measures the direct sunlight, scattering, and marginal light [1]. There is the aerosol parameter distribution on a global scale like AERONET: Aerosol Robotic Network and SKYNET: Sky-radiometer Network by developing the sky-radiometer all around the world, and aerosol which is a contributing factor of earth radiation budget, global warming etc. Attempts have been made to elucidate the wide area distribution of. In that case, the calibration accuracy of the sky-radiometer greatly affects the aerosol complex refractive index and the estimation accuracy of the particle size distribution, which is extremely important.

Solar irradiance measurement on the ground is a very effective method for knowing the optical and physical properties of the sun and the Earth's atmosphere [2]-[4]. The first of this method is the Langley plot method based on the Beer Bouquet Lambert's rule [5]: LPM [6]. Measure the direct sunlight from sunrise to southern middle time to estimate the atmospheric mass to 0 , that is, to estimate radiance outside the solar atmosphere. A calibration method has been proposed to determine the calibration coefficient of the sky-radiometer so that the difference between this estimated value and the stable solar atmospheric radiance and irradiance model [5] called socalled solar constant is 0 , which is widely used [7], [8]. In addition, a method of reducing the influence of noise in observation has been proposed [9].

The calibration of the sky-radiometer has dealt with the Rati Langley method [10] which aimed at improving the calibration accuracy by obtaining the calibration coefficient according to the ratio between the LPM and the measurement wavelength, and the fluctuation of the atmospheric condition in the Langley plot This is done by the modified Langley method (ILM [11]). LPM is effective when the atmospheric condition does not change, but such a state is difficult to obtain, generally it is not possible to expect high calibration accuracy. ILM measures not only direct sunlight but also scattering and marginal light on the ground surface, estimates the optical thickness of air molecules, ozone, aerosol, aerosol complex index of refraction, and particle size distribution, and obtains the scattering phase function from these The scattering contribution component is estimated and the calibration coefficient of the sky-radiometer is determined with the downward radiance on the ground where the value obtained by multiplying the aerosol optical thickness by the atmospheric mass becomes zero. Therefore, since ILM does not assume stability of atmospheric condition for a long time compared with LPM, relatively high calibration accuracy can be expected.

In addition, the RLM utilizes the fact that the logarithm of the optical thickness and the logarithm of the wavelength are in a linear relationship, and by taking into account the aerosol particle size distribution by the aerosol optical thickness at a certain reference wavelength, an aerosol of any arbitrary wavelength and estimates the optical thickness. The calibration coefficient of the sky-radiometer is determined by the downward radiance (irradiance) on the ground where the proportional coefficient of the linear relation is multiplied by the aerosol optical thickness at the reference wavelength and the atmospheric mass to zero. 
This research aimed at newly devising a calibration method that combines the merits of ILM and RLM and to further improve the calibration accuracy. In other words, I propose a method that achieves high calibration accuracy over all wavelengths by exploiting the features of ILM with high calibration accuracy in the relatively long wavelength region, and using this as the reference wavelength of RLM to obtain calibration coefficients of other arbitrary wavelengths

At this time, consider the aerosol particle size distribution. That is, the volume spectrum [11] is reanalyzed using sunlight and marginal light radiance. I evaluated the proposed method based on measured numerical simulation and measured values themselves, and ascertained the superiority over the existing method, I report here. Section 2 introduces LPM, ILM and RLM as a theoretical background on calibration of skyradiometer, and explains the proposed method in Section 3. In addition, the numerical simulation method and results in Section 4 and the advantage of the proposed method based on measured data are shown in Section 5.

\section{PROPOSED METHOD}

\section{A. Theoretical Background}

LPM observes the sun's direct light $F$ from the sunrise to the south middle and estimates the radiance $F_{0}$ of the sun's atmosphere outside from (1).

$$
\ln F=\ln F_{0}-m \tau
$$

where $F$ and $F_{0}$ are the direct solar radiation radiance on the earth's surface and the sun's atmospheric radiance outside the atmosphere, $\tau$ is the optical thickness of the whole atmosphere and $m$ is the atmospheric mass. It is a precondition that the optical thickness of the whole atmosphere does not change during observation time for that reason,

As a result, LPM is effective only at high-altitude sites where the atmosphere is clear and stable with consistent conditions. In addition, the calibration accuracy of measuring equipment for solar direct light is also important. This is evident from the fact that it appears as an estimation error of the calibration coefficient of 2.6 to $10 \%$ [12] as it is clear from the past study evaluating the influence of the calibration precision in the plural aerosol models. ILM based on simultaneous observation of sunlight and marginal light was proposed to cope with the atmospheric condition variation in the Langley plot. The optical thickness of the aerosol is estimated by Volume Spectrum Analysis (VSA). At VSA, solar marginal light is replaced by the relative radiance of (2).

$$
R(\theta)=\frac{F(\theta)}{F m \Delta \Omega}=\omega \not P(\theta)+q(\theta)
$$

where, $R(\theta)$ at the angle $\theta$ is the relative radiance at the angle $\theta$ normalized by the solar direct ray $F$ of the sun marginal light: $F(\theta), \Delta \Omega$ is the small solid angle, $\omega$ is the single scattered albedo, and $q(\theta)$ is multiple scattering component. Also,
$P(\theta)$ is the scattering phase function of the aerosol and the air molecule at the scattering angle $\theta$, and is defined by (3).

$$
P(\theta)=\left(\omega_{a} \tau_{a} P_{a}(\theta)+\omega_{m} \tau_{m} P_{m}(\theta)\right) / \omega \tau
$$

where, $\omega_{a}, \tau_{a}$ and $P_{a}(\theta)$ are the single scatter albedo, optical thickness and phase function of the aerosol, and $\omega_{m}$, $\tau_{m}$ and $P_{m}(\theta)$ are those of the air molecule. If the aerosol particles are spherical homogeneous, from the Mie scattering theory $\omega_{a} \tau_{a} P_{a}(\theta)$ is defined by (4).

$$
\omega_{a} \tau_{a} P_{a}(\theta)=\int_{r 1}^{r 2} K(\theta, k r, \tilde{m}) v(r) d \ln r
$$

where, $v(r)=(4 \pi / 3) r^{4} n(r)$, and $n(r)$ is the vertical particle size distribution of the aerosol. In addition, $k=2 \pi / \lambda$ and $\tilde{m}=n-i \xi$ is the aerosol complex index of refraction, $K_{\text {ext }}(k r, \tilde{m}), \quad K(\theta, k r, \tilde{m})$ is the integral kernel function defined by Mie scattering theory. An approximate solution of the aerosol volume spectrum $v(r)$ is obtained by using a radiative transfer inversion that iteratively updates the multiple scattering contribution $q(\theta)$ according to the measurement value of the sun marginal light [11]. In this way the aerosol optical thickness can be estimated by (5).

$$
\tau_{a}=\int_{r 1}^{r 2} K_{e x t}(k r, \tilde{m}) v(r) d \ln r
$$

By rewriting equation (1),

$$
\ln F+m\left(\tau_{m}+\tau_{o}\right)=\ln F_{0}-m \tau_{a}
$$

where, $\tau_{o}$ is the optical thickness of ozone. Therefore, the calibration coefficient is obtained when $m \tau_{a}=0$. This method is called a modified Langley method (ILM). This method excludes most of the influence on atmospheric state change in aerosol optical thickness estimation by solar marginal light observation and is superior to LPM with deterioration of calibration coefficient estimation accuracy due to atmospheric state change. Fig. 1 shows comparison between LPM and ILM.

In this figure, despite the total atmospheric optical thicknesses being both 0.1 and 0.2 , the estimated value of radiance outside the solar atmosphere is not matched because of the calibration problem in the case of LPM, but in the case of ILM, the radiance outside the solar atmosphere is matched when both the optical thicknesses are 0.1 and 0.2 .

$$
\ln F / m=\ln F_{0} / m-\tau
$$

The proposed method deforms (1) to reduce the influence due to temporal and spatial atmospheric conditions [13]. 


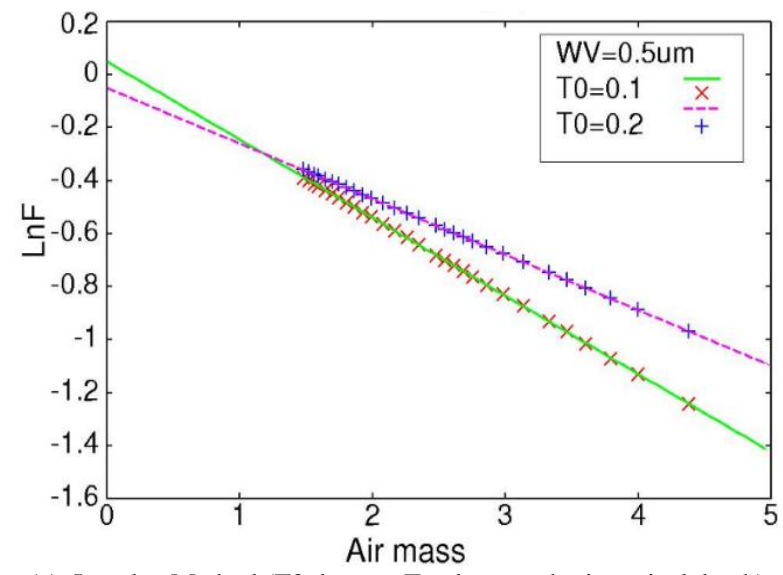

(a) Langley Method (T0 denotes Total atmospheric optical depth)

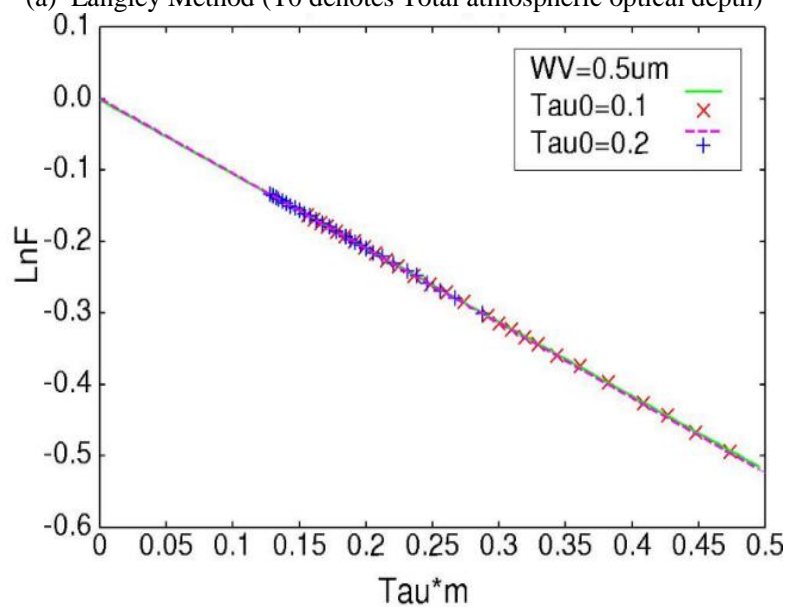

(b) Improved Langley Method (ILM), Tau0 denotes

Fig. 1. Illustrative comparison between Langley method and Improved Langley Method (ILM).

It is also applied to measurement data of Multi-Filter Rotating Shadow Band Radiometer (MFRSR) [14] and is trying to use it for atmospheric correction [15]. Furthermore, accuracy comparison with regular LPM has also been done, proving that the precision according to (7) is higher [9].

\section{B. Proposed Method}

In solving the radiative transfer equation by inversion due to influences such as the brightness of marginal light $\theta<30^{\circ}$, scattering by air molecules, error in peripheral light measurement, volume spectrum estimation error, other assumptions about atmospheric conditions, etc. The effect of multiple scattering tends to be estimated low. These errors appear when VSA estimates the aerosol optical thickness. An example is shown in Fig. 2.

Aerosol optical thickness was measured at Saga University under fine weather on November 26, 2003, December 3 and December 4, 2003 by the Sky-radiometer POM-1 manufactured by PREDE Co. Ltd. This figure compares the aerosol optical thickness estimated by VSA and the volume spectrum obtained by reanalysis using the measurement result by the Sky-radiometer. The difference between them is as much as $10 \%$, which means that the calibration coefficient estimation accuracy obtained by ILM will be low. The figure also shows that the difference between the aerosol optical thicknesses of both is smaller in the long wavelength region than in the short wavelength, meaning that the accuracy is higher when the calibration coefficient is obtained in the long wavelength region.

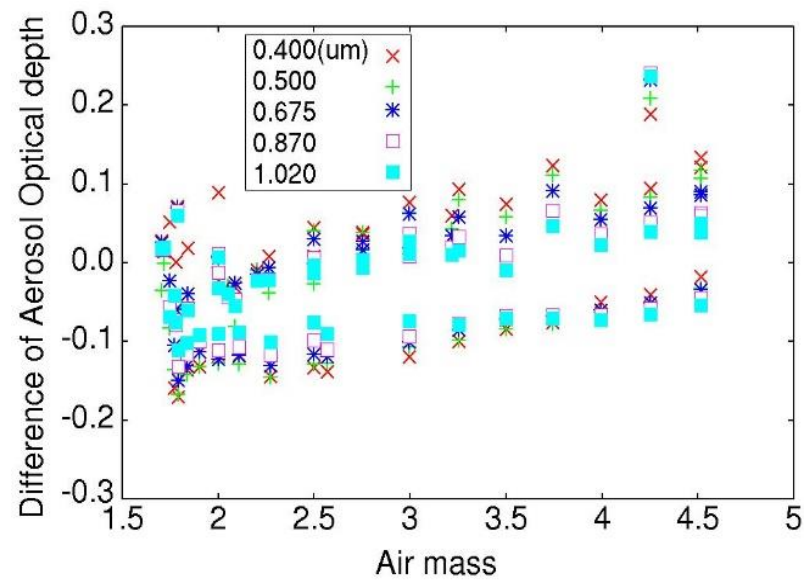

Fig. 2. The Differences of aerosol optical depth by means of VSA and reanalysis of volume spectrum from air-mass 1.5 to 4.5 . Data are observed by POM-1 Sky-radiometer in 11/26/2003, 12/03/2003 and 12/04/2003 at Saga, Japan.

Fig. 3 shows the minimum of the estimated sunlight direct radiance when the measurement error is $\pm 10 \%$ for the optical thickness change range (0.08 to 0.28$)$ under the typical atmospheric condition of Fig. 2 (L2) and the maximum (L1) logarithm. When compared with the case without error, it is found that there is a difference of $-2 \%$ between the former and the $+3 \%$ from the latter. In other words, it means that the measurement accuracy of the optical thickness of $\pm 10 \%$ appears as the logarithm difference of the direct solar radiation radiance of $5 \%$.

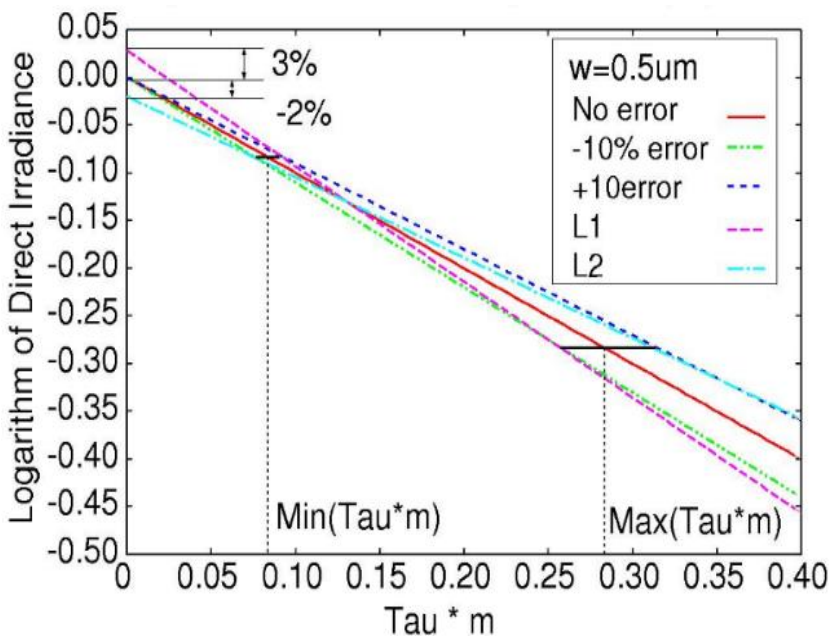

Fig. 3. Importance of optical depth measurement accuracy for Improved Langley Method: ILM.

From the aerosol optical thickness at a certain reference wavelength, there is a method of obtaining it from other wavelengths in consideration of the particle size distribution $f(r)$ [10]. This method is called RLM. At this time, the aerosol optical thickness can be obtained by multiplying the 
particle diameter distribution by the logarithm of the particle diameter $r$ and integrating by multiplying by the kernel function.

$$
\tau_{a}(\lambda, t)=\pi A(t) \int K_{e x t}(r, \lambda) f(r) d \ln r
$$

Therefore, the ratio of the aerosol optical thickness at different wavelengths is a constant as in equation (9).

$$
\tau_{a}\left(\lambda_{1}, t\right) / \tau_{a}\left(\lambda_{2}, t\right)=\tau_{a}\left(\lambda_{1}, t_{0}\right) / \tau_{a}\left(\lambda_{2}, t_{0}\right)=\psi
$$

where, $A(t)$ is a constant for deriving the actual particle shape distribution from the particle size distribution shape at time t. From these, it is found from the calibration coefficient at the reference wavelength at other wavelengths.

$$
\ln F\left(\lambda_{1}\right)+m\left(\tau_{m}\left(\lambda_{1}\right)+\tau_{o}\left(\lambda_{1}\right)\right)=\ln F_{0}\left(\lambda_{1}\right)-\psi m \tau_{a}\left(\lambda_{0}\right)
$$

where, $\lambda_{0}, \lambda_{1}$ is the reference and calibration wavelength, and $\psi$ is a constant. Since $m \tau_{a}\left(\lambda_{0}\right)$ is well calibrated, $\ln F_{0}\left(\lambda_{1}\right)$ can be obtained by regression analysis with the left side of (10) and $m \tau_{a}\left(\lambda_{0}\right)$.

The proposed calibration method calibrates based on the ILM in the long wavelength region where the calibration accuracy is relatively high and uses the result as the reference wavelength calibration coefficient to obtain calibration coefficients of other wavelengths. At this time, the Skyradpack software code [11] was used when ILM was applied. The flow of the proposed calibration method is shown in Fig. 4.

First, based on Skyradpack ver. 4.2, VSA is obtained by using measurement data by Sky-radiometer, and aerosol optical thickness and volume spectrum are calculated. At this time, the calibration of the sky-radiometer is performed by ILM. Next, the volume spectrum is reanalyzed using the direct sunlight and the peripheral light radiance to re-calculate the aerosol optical thickness, the volume spectrum, the complex refractive index and the like with higher accuracy. Calibration is performed at other wavelengths based on the calibration coefficients at various amounts and reference wavelengths obtained by these reanalyzes. These are performed in two stages of levels 0 and 1 shown below.

Level 0: Estimate volume spectrum based on VSA. The aerosol optical thickness is obtained using the sunlight directly and peripheral measurement data. Calibrate $F_{0}$ from the plot until $\ln F-m \quad \tau$ a becomes zero.

Level 1: Re-analyze the sunlight and marginal light, volume spectrum, update the VSA, and recalculate the phase function and volume spectrum.

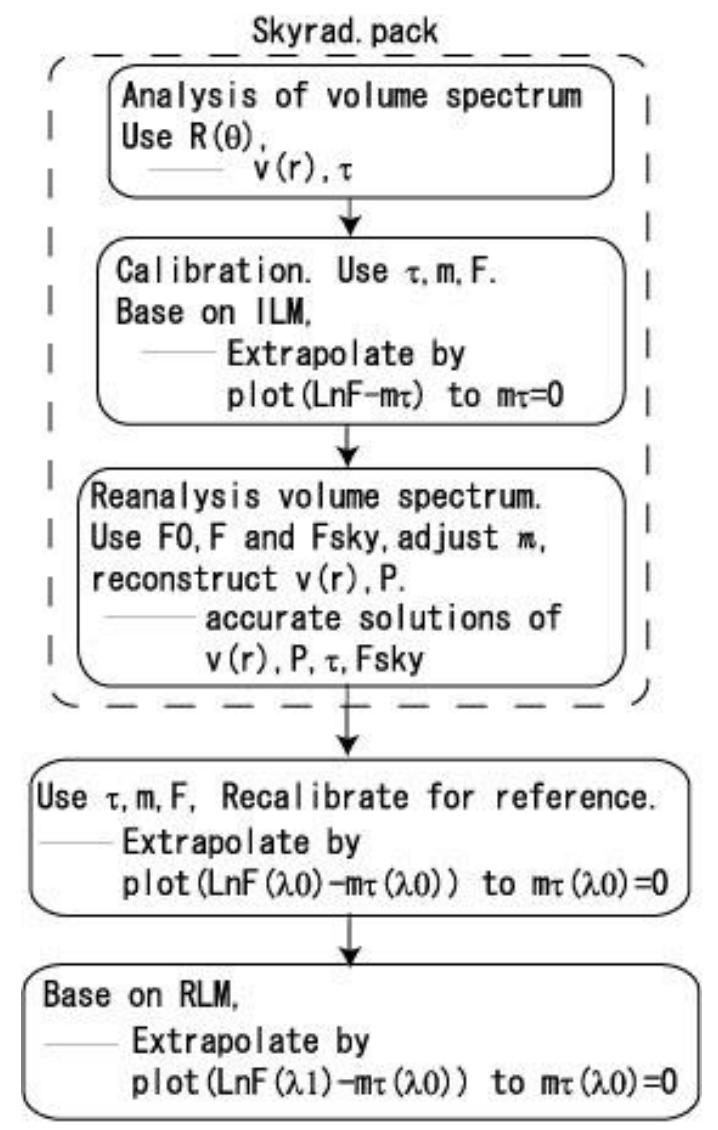

Fig. 4. The algorithm of multi stage calibration method.

\section{SiMULATION}

Simulation data was generated based on Skyradpack ver.4.2 mentioned above. The wavelength to be used is the set wavelength of the Sky-radiometer POM-1 manufactured by PREDE Co. Ltd., 0.4, 0.5, 0.675, 0.87 and $1.02 \mu \mathrm{m}$. The reference wavelength was set to $0.87 \mu \mathrm{m}$ which is a long wavelength. In addition, the lognormal distribution of (11) was assumed for the particle size distribution of aerosol.

$$
n(\ln r)=\sum_{i=1}^{2} \frac{C_{i}}{\sqrt{2 \pi} \log \sigma_{i}} \exp \left(-\frac{\left(\log r-\log \bar{r}_{i}\right)^{2}}{2 \log ^{2} \sigma_{i}}\right)
$$

where $n(\ln r) d \ln r$ is the number density of aerosol particles between particle size $r$ and $r+d l n r$. Also $C_{i}$ set to 1 , the standard deviation and average $\sigma_{i}, \bar{r}_{i}$ of the particle size distribution was set to be the same as the aerosol type measured at Saga University in 2003. These amounts are shown in Table I. 
TABLE I. THE PARAMETERS FOR LOG-NORMAL DISTRIBUTION

\begin{tabular}{|l|l|l|l|}
\hline No. Mode & $\mathrm{C}_{\mathrm{i}}$ & $\mathrm{r}_{\mathrm{i}}(\mu \mathrm{m})$ & $\sigma_{\mathrm{i}}$ \\
\hline 1 & 1 & 0.37 & 1.95 \\
\hline 2 & 1 & 3.06 & 2.36 \\
\hline
\end{tabular}

That is, the particle size distribution is a bimodal characteristic (bimodal), with the first mode appearing at 0.37 $\mu \mathrm{m}$ and the second mode at $3.06 \mu \mathrm{m}$. Furthermore, the aerosol complex refractive index is set to $m=1.50-0.01 i$, and the radiance of the sun outside the atmosphere is set to 1 . The temporal variation of the aerosol optical thickness was assumed to conform to (12) [16].

$\tau_{a}=\tau_{a 0}\left(1+\alpha t^{2}\right)$

where, $\tau_{a 0}$ is the aerosol optical thickness at the southmiddle time, and they were set to $0.1,0.2$ and 0.3 by numerical simulation. Also, $\alpha$ is assumed to be 0.011 . Thus, the aerosol optical thickness will vary from 0 to $20 \%$, whereas the atmospheric mass varies between 1.5 and 4.5. An error (random noise) of $\pm 3 \%$ and $\pm 5 \%$ was intentionally superimposed on the measured value of the Sky-radiometer. Simulation results are shown in Fig. 5. In the figure, the wavelengths are limited to $0.4,0.5$ and $0.87 \mu \mathrm{m}$ to avoid expression complexity. These are the ILM, VSA $\left(\mathrm{L}_{0}\right.$ in the figure) and the proposed method, i.e. the estimation error of the aerosol optical thickness ( $\mathrm{L}_{1}$ in the figure) obtained by reanalysis of the volume spectrum. At this time, the total atmospheric optical thickness was set to $0.1,0.2,0.3$. Measurement errors of $0 \%, \pm 3 \%$ and $\pm 5 \%$ were randomly superimposed on the radiance measured by the Sky-radiometer.

Table II shows the maximum of the estimation error of aerosol optical thickness by ILM, that is VSA. From this table the accuracy of estimating the aerosol optical thickness of ILM is more sensitive to the measurement error superimposed on the sky-radiometer than the optical thickness of the whole atmosphere.

TABLE II. MaXimum ERror in Aerosol Optical Depth Estimation with the Methods By (A) VSA and By (B) ReANALysis of Volume Spectrum AS THE OPTICAL DEPTH OF $0.1,0.2$ AND 0.3

\begin{tabular}{|c|c|c|c|c|c|c|c|c|c|c|c|}
\hline & & \multirow{8}{*}{$\begin{array}{l}\text { Optical Depth } \\
\text { Wavelength(nm) }\end{array}$} & \multicolumn{3}{|l|}{0.1} & \multicolumn{3}{|l|}{0.2} & \multicolumn{3}{|l|}{0.3} \\
\hline Error(\%) & Method & & 400 & 500 & 870 & 400 & 500 & 870 & 400 & 500 & 870 \\
\hline 0 & \multirow{3}{*}{ LM } & & 0.025 & 0.015 & 0.007 & 0.042 & 0.025 & 0.009 & 0.042 & 0.024 & 0.009 \\
\hline \pm 3 & & & 0.09 & 0.05 & 0.028 & 0.063 & 0.036 & 0.022 & 0.057 & 0.033 & 0.026 \\
\hline \pm 5 & & & 0.14 & 0.07 & 0.045 & 0.1 & 0.045 & 0.038 & 0.081 & 0.038 & 0.038 \\
\hline 0 & \multirow{3}{*}{ PM } & & -0.015 & -0.011 & -0.003 & -0.013 & -0.01 & -0.003 & 0.042 & 0.033 & 0.013 \\
\hline \pm 3 & & & 0.058 & 0.025 & 0.024 & 0.045 & 0.02 & 0.025 & 0.044 & 0.02 & 0.014 \\
\hline \pm 5 & & & 0.058 & -0.038 & $\begin{array}{l}-0.02 \\
\end{array}$ & -0.042 & -0.03 & -0.02 & -0.038 & -0.032 & -0.021 \\
\hline
\end{tabular}

Table II and Fig. 5 also show that

a) estimation of aerosol optical thickness by reanalysis of volume spectrum is more accurate than by VSA,

b) estimation of aerosol optical thickness at $0.87 \mu \mathrm{m}$

c) the influence of measurement error depends largely on the case of VSA and not sensitive for volume spectrum reanalysis,

d) optical thickness: The same is true for the influence on VSA, in the case of VSA, the estimation error of the aerosol optical thickness depends on the optical thickness, but in the case of reanalysis of the volume spectrum the dependence is small. Aureole is discussed in the previous paper [17].

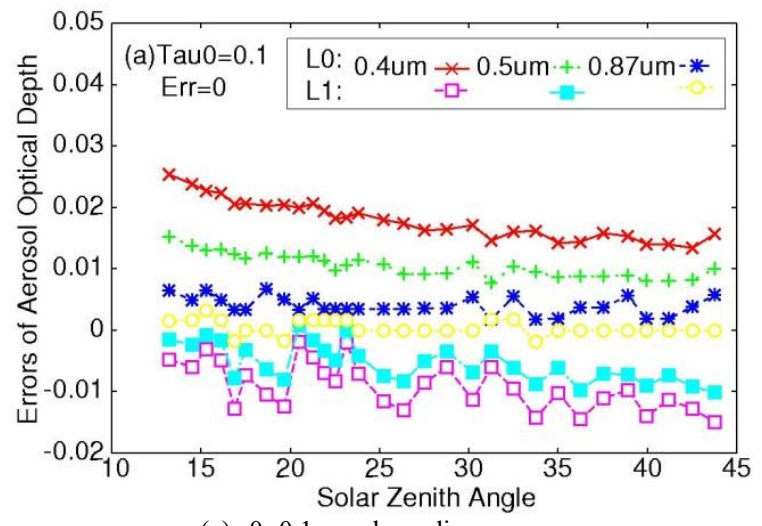

(a) $\tau 0=0.1$, no sky radiance error

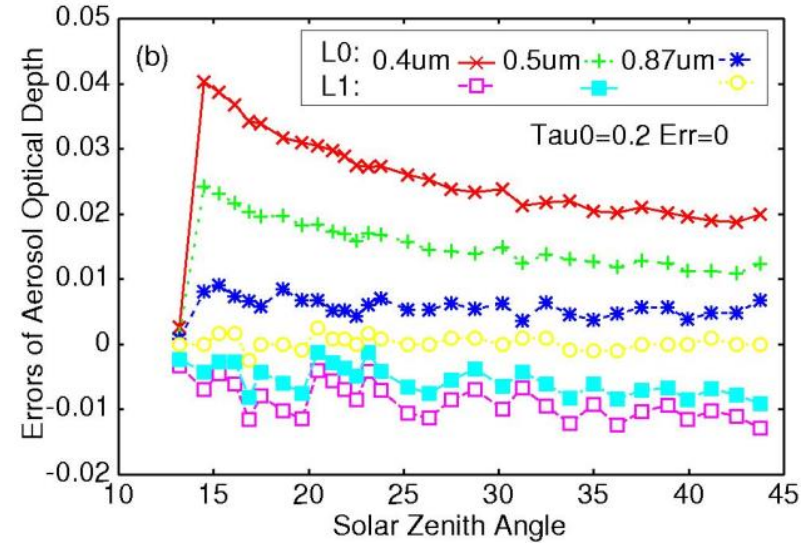

(b) $\tau 0=0.2$, no sky radiance error

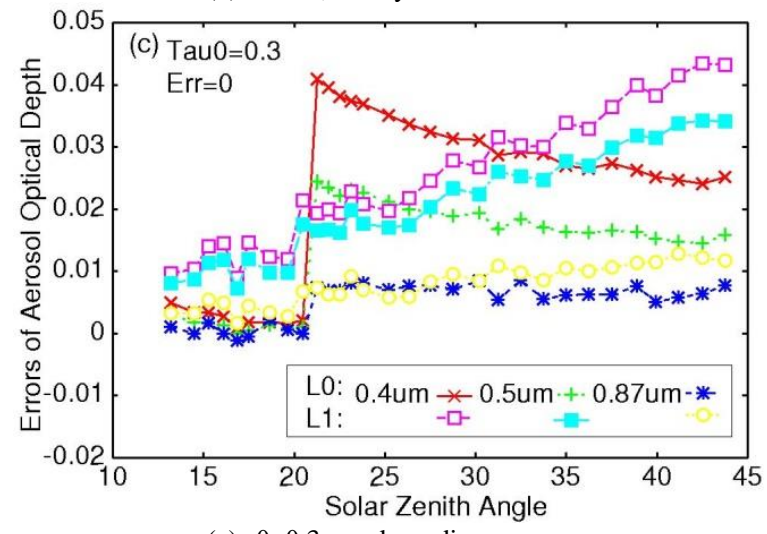

(c) $\tau 0=0.3$, no sky radiance error 


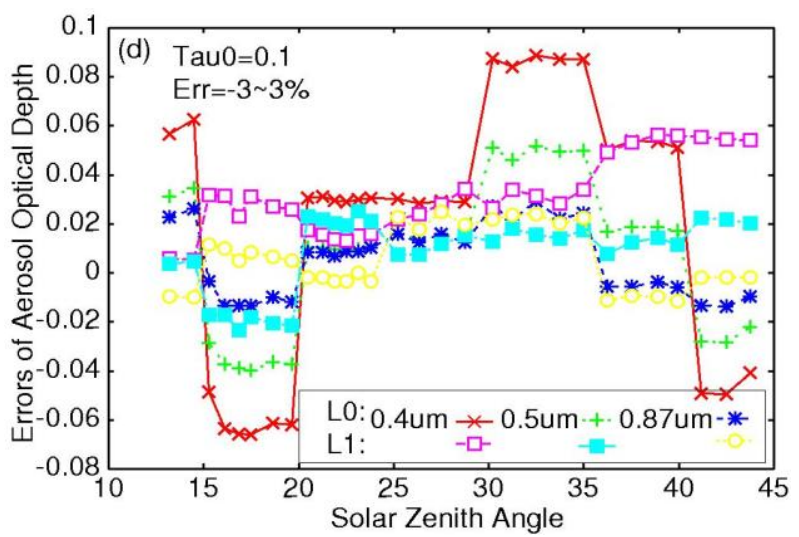

d) $\tau 0=0.1, \pm 3 \%$ of sky radiance error

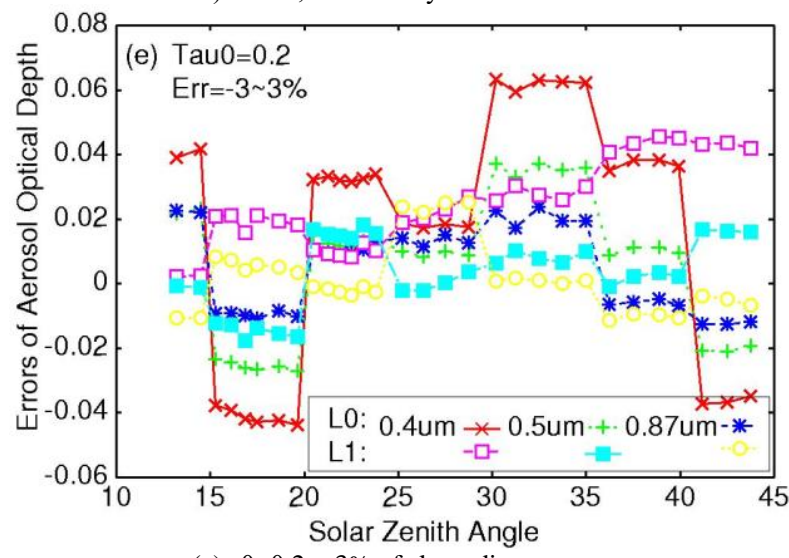

(e) $\tau 0=0.2, \pm 3 \%$ of sky radiance error

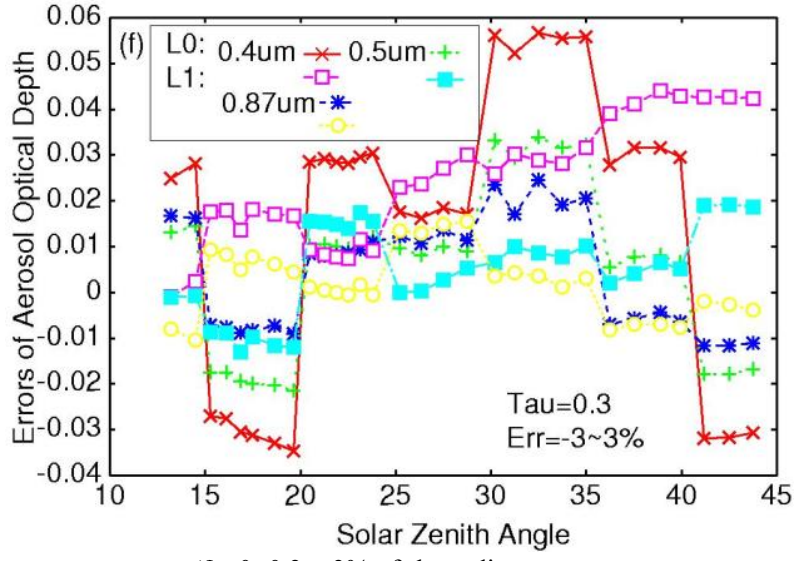

(f) $\tau 0=0.3, \pm 3 \%$ of sky radiance error

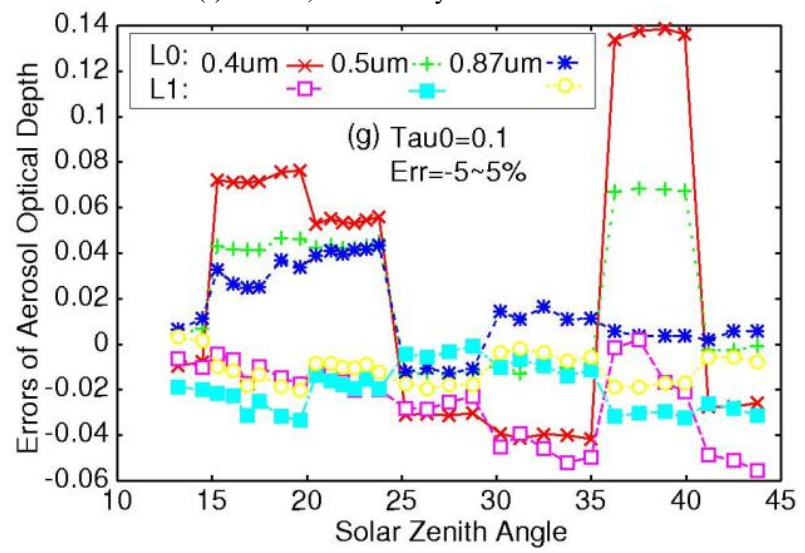

(g) $\tau 0=0.1, \pm 5 \%$ of sky radiance error

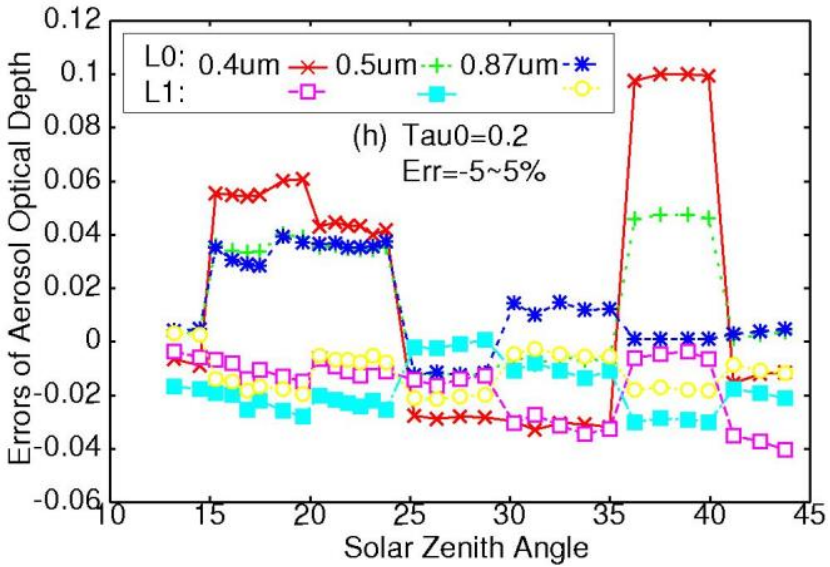

(h) $\tau 0=0.2, \pm 5 \%$ of sky radiance error

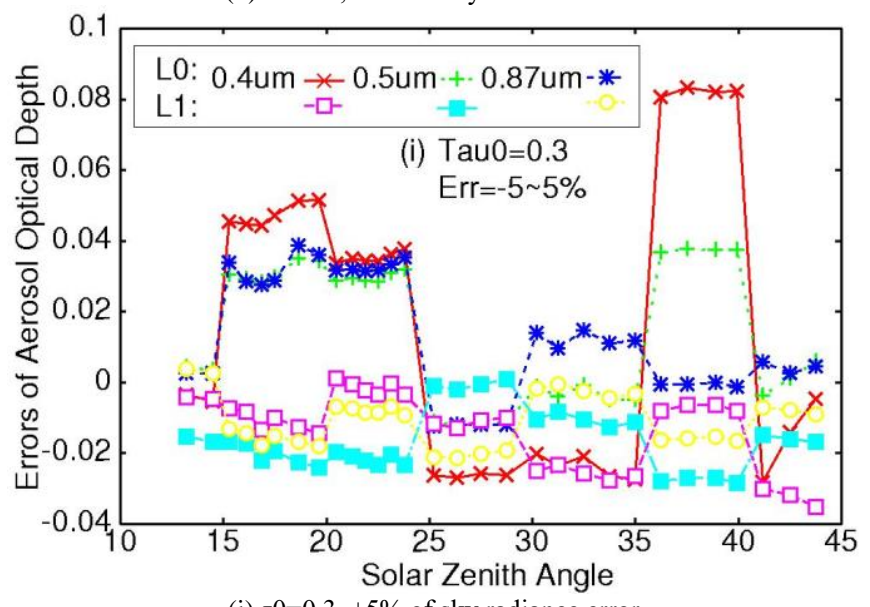

(i) $\tau 0=0.3, \pm 5 \%$ of sky radiance error

Fig. 5. The estimation errors of aerosol optical depth with VSA and reanalysis of volume spectrum for the wavelengths $0.4,0.5$ and $0.87 \mathrm{um}$ with 0 , $\pm 3 \%$ and $\pm 5 \%$ of random noise in sky radiance measurements.

Table III compares the calibration coefficient estimation accuracy by ILM and the proposed method for five wavelengths. The calibration accuracy of the proposed method exceeds ILM especially at short wavelength $(0.4 \mu \mathrm{m})$. Also, as the optical thickness increases, the more the noise superimposed on the measurement of the sky-radiometer, the greater the difference in calibration coefficient accuracy between ILM and the proposed method.

TABLE III. COMPARISON OF ESTIMATION ERROR FOR CALIBRATION BETWEEN ILM (USE VSA) AND THE PROPOSED METHOD (PM: USE REANAlysis OF VOlUME SPECTRUM) AS THE OPTICAL DEPTH ARE 0.1, 0.2 AND 0.3

(a) $0 \%$ Error
\begin{tabular}{|l|l|l|l|l|l|l|}
\hline $\begin{array}{l}\text { Aerosol Optical } \\
\text { Depth }\end{array}$ & \multicolumn{2}{l|}{0.1} & \multicolumn{2}{l|}{0.2} & \multicolumn{2}{l|}{0.3} \\
\hline Wavelength(nm) & LM & PM & LM & PM & LM & PM \\
\hline 400 & 0.0008 & $\begin{array}{l}0.000 \\
6\end{array}$ & $\begin{array}{l}0.002 \\
9\end{array}$ & $\begin{array}{l}0.000 \\
9\end{array}$ & $\begin{array}{l}0.01 \\
3\end{array}$ & $\begin{array}{l}0.001 \\
4\end{array}$ \\
\hline 500 & 0.0003 & $\begin{array}{l}0.000 \\
6\end{array}$ & $\begin{array}{l}0.001 \\
5\end{array}$ & $\begin{array}{l}0.000 \\
6\end{array}$ & 0.01 & $\begin{array}{l}0.000 \\
9\end{array}$ \\
\hline 675 & 0.0012 & $\begin{array}{l}0.000 \\
5\end{array}$ & $\begin{array}{l}0.000 \\
6\end{array}$ & $\begin{array}{l}0.000 \\
6\end{array}$ & $\begin{array}{l}0.00 \\
5\end{array}$ & $\begin{array}{l}0.000 \\
5\end{array}$ \\
\hline 870 & 0.0002 & $\begin{array}{l}0.000 \\
2\end{array}$ & $\begin{array}{l}0.000 \\
1\end{array}$ & $\begin{array}{l}0.000 \\
1\end{array}$ & $\begin{array}{l}0.00 \\
3\end{array}$ & $\begin{array}{l}0.000 \\
4\end{array}$ \\
\hline 1020 & 0.0002 & $\begin{array}{l}0.000 \\
2\end{array}$ & $\begin{array}{l}0.000 \\
1\end{array}$ & $\begin{array}{l}0.000 \\
1\end{array}$ & $\begin{array}{l}0.00 \\
2\end{array}$ & $\begin{array}{l}0.000 \\
4\end{array}$ \\
\hline
\end{tabular}


(b) $\pm 3 \%$ Error

\begin{tabular}{|l|l|l|l|l|l|l|}
\hline Aerosol Optical Depth & \multicolumn{1}{|l|}{0.1} & \multicolumn{2}{l|}{0.2} & \multicolumn{2}{l|}{0.3} & \\
\hline Wavelength(nm) & LM & PM & LM & PM & LM & PM \\
\hline 400 & 0.011 & 0.004 & 0.017 & 0.009 & $\begin{array}{l}0.02 \\
3\end{array}$ & 0.011 \\
\hline 500 & 0.008 & 0.003 & 0.009 & 0.006 & $\begin{array}{l}0.01 \\
2\end{array}$ & 0.009 \\
\hline 675 & 0.003 & 0.002 & 0.003 & 0.002 & $\begin{array}{l}0.01 \\
5\end{array}$ & 0.007 \\
\hline 870 & 0.006 & 0.002 & 0.001 & 0.001 & $\begin{array}{l}0.00 \\
2\end{array}$ & 0.001 \\
\hline 1020 & 0.002 & 0.001 & 0.001 & 0.002 & $\begin{array}{l}0.00 \\
1\end{array}$ & 0.001 \\
\hline
\end{tabular}

(c) $\pm 5 \%$ Error

\begin{tabular}{|l|l|l|l|l|l|l|}
\hline $\begin{array}{l}\text { Aerosol Optical } \\
\text { Depth }\end{array}$ & \multicolumn{2}{l|}{0.1} & \multicolumn{2}{l|}{0.2} & \multicolumn{2}{l|}{0.3} \\
\hline Wavelength(nm) & LM & PM & LM & PM & LM & PM \\
\hline 400 & 0.013 & 0.007 & 0.018 & 0.005 & $\begin{array}{l}0.02 \\
7\end{array}$ & 0.014 \\
\hline 500 & 0.006 & 0.006 & 0.006 & 0.004 & $\begin{array}{l}0.01 \\
1\end{array}$ & 0.01 \\
\hline 675 & 0.003 & 0.003 & 0.003 & 0.003 & $\begin{array}{l}0.00 \\
7\end{array}$ & 0.005 \\
\hline 870 & 0.001 & 0.001 & 0.002 & 0.001 & $\begin{array}{l}0.00 \\
1\end{array}$ & 0.001 \\
\hline 1020 & 0.001 & 0.001 & 0.002 & 0.001 & $\begin{array}{l}0.00 \\
1\end{array}$ & 0.002 \\
\hline
\end{tabular}

In order to investigate the influence of particle size distribution on calibration accuracy, the average and standard deviation of the relative particle size distribution of equation (10) were varied by $\pm 3 \%$ and $\pm 5 \%$. An example of the particle size distribution recalculated by reanalysis is shown in Fig. 6.

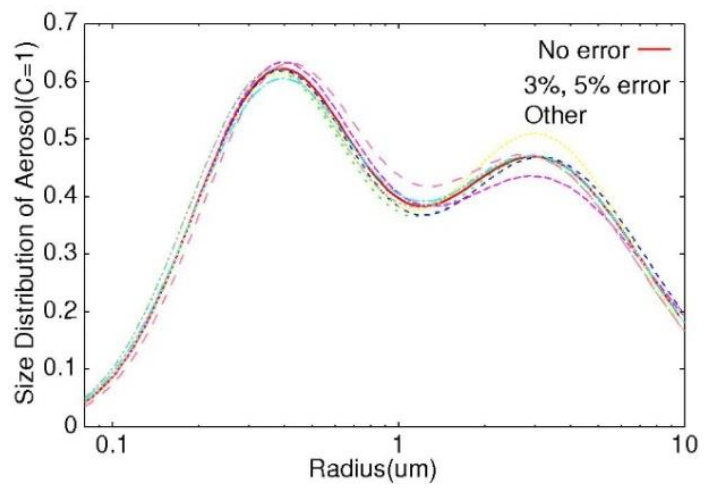

Fig. 6. Size distribution error due to $\pm 3 \%$ and $\pm 5 \%$ of sky radiance measurement errors.

From this figure, it can be seen that the measurement error of the standard deviation of 3,5\% appears as a difference in volume spectra of $0.61 \pm 3.3 \%$ at $0.37 \mu \mathrm{m}$ in the first mode and $0.47 \pm 8.5 \%$ at $3.06 \mu \mathrm{m}$ in the second mode. Conversely, calibration accuracy is improved by reflecting this amount on the aerosol optical thickness by this amount.

\section{EXPERIMENT}

Direct scattering, scattering and marginal light were measured using the sky-radiometer POM - 1 shown in Fig. 7. I am continuing the measurement from September 2003 to the present, but here it is assumed that 15 data sets measured under fine weather conditions (on 16, 17, 23 November 2003, 03, 04, 24 December 2003, 07, 08, 31 January 2004, 20 February 2004, 15 March 2004, 05, 22, 24, 25 April 2004).

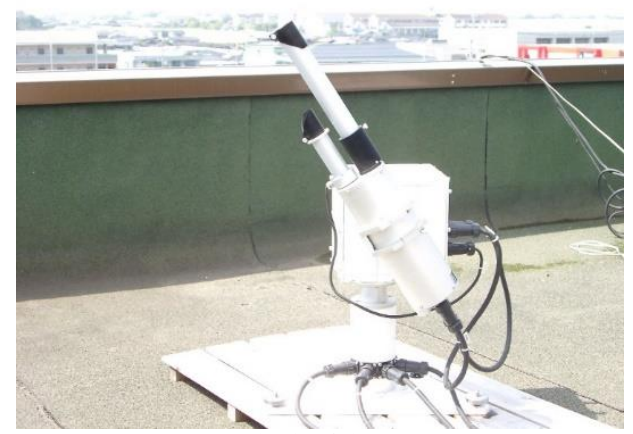

(a) Outlook of the POM-1

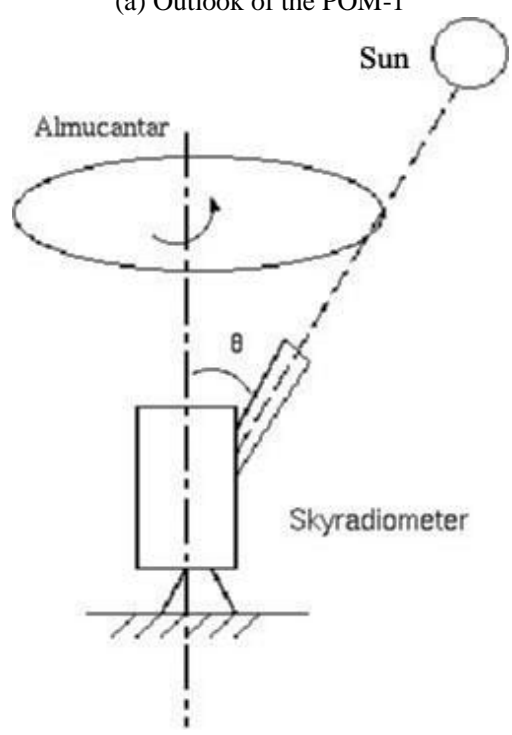

(b) Observation scheme

Fig. 7. Observation scheme (Almucantar observation for direct, diffuse and aureole measurements) and outlook of the sky-radiometer, POM-1 which is put on the top of the building of the Saga University at $130^{\circ} 29^{\prime} \mathrm{E}, 33^{\circ} 25^{\prime} \mathrm{N}$.

The effectiveness of the proposed method was verified. Here, the optical thickness of the atmosphere was 0.3 or less at $0.5 \mu \mathrm{m}$. Also, the ratio of the optical thickness ratio at two different wavelengths was within $5 \%$.

The calibration result at the reference wavelength of 0.87 $\mu \mathrm{m}$ by ILM is shown in Fig. 8 .

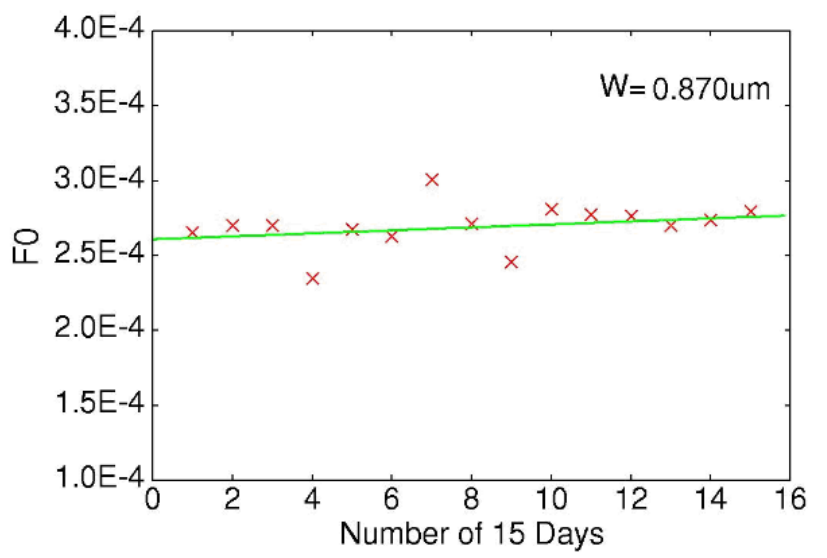

Fig. 8. $\quad \mathrm{F}_{0}$ measured with Improved Langley method for 15 days of measured solar direct, diffuse and aureole. 


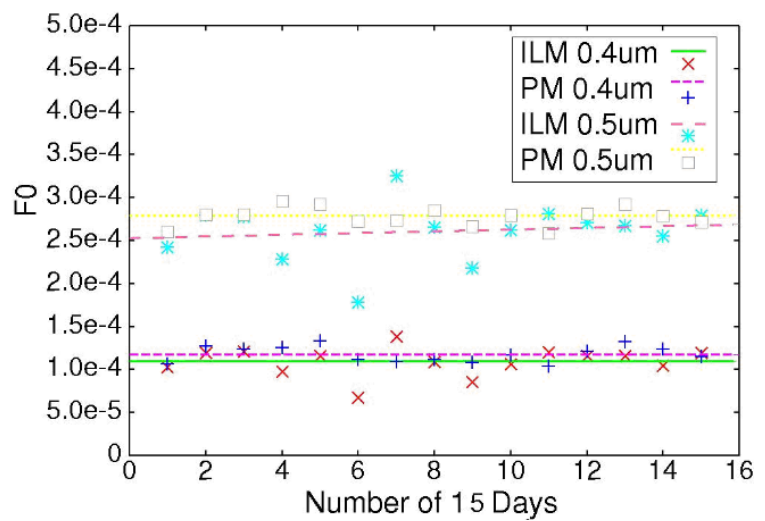

Fig. 9. Comparison between ILM and the proposed method (PM) at bands 0.4 and $0.5 \mu \mathrm{m}$ for 15 days of measured solar direct, diffuse and aureole.

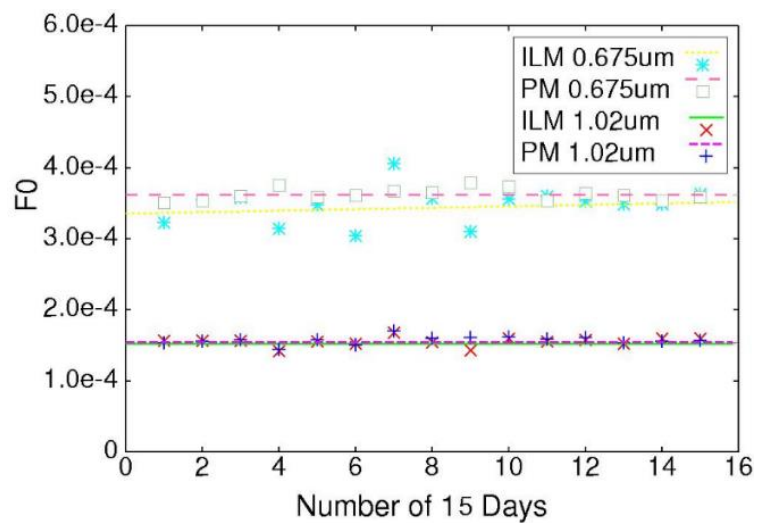

Fig. 10. Comparison between ILM and the proposed method (PM) at bands 0.675 and $1.02 \mu \mathrm{m}$ for 15 days of measured solar direct, diffuse and aureole.

As is apparent from the figure, the standard deviation of the calibration value of $\mathrm{F}_{0}$ is within $1 \%$, indicating that the accuracy is extremely high. Calibration results of ILM and the proposed method are shown in Fig. $9(0.4,0.5 \mu \mathrm{m})$ and Fig. 10 $(0.675,1.02 \mu \mathrm{m})$.

As is evident from these figures, it can be demonstrated that the proposed method has higher calibration accuracy than ILM. Whether the calibration accuracy is good or bad is evaluated based on the standard deviation of the calibration value of $\mathrm{F}_{0}$ is shown in Table IV, and it was confirmed that the calibration accuracy improvement ranged from $8.22 \%$ to $47.75 \%$. The effect of improving the calibration accuracy is high in the short wavelength region as can be understood from the principle. From this, it can be said that calibration by the proposed method requires less calibration frequency for the same calibration accuracy requirement.

TABLE IV. COMPARISON OF THE STANDARD DEVIATIONS BETWEEN ILM AND PM

\begin{tabular}{|l|l|l|l|}
\hline \multirow{2}{*}{ Wavelength $(\boldsymbol{\mu m})$} & \multicolumn{2}{|l|}{ Standard Deviation } & \multirow{2}{*}{ \% Improve } \\
\cline { 2 - 3 } & ILM & PM & Ratio \\
\hline 0.4 & 0.03858 & 0.02016 & 47.745 \\
\hline 0.5 & 0.02219 & 0.01691 & 23.795 \\
\hline 0.675 & 0.01837 & 0.01295 & 29.505 \\
\hline 1.02 & 0.01022 & 0.00938 & 8.219 \\
\hline
\end{tabular}

\section{CONCLUSION}

Improved Langley method (ILM): In order to improve the calibration accuracy of the Sky-radiometer by ILM, attention is paid to the fact that the ILM has a high calibration accuracy at a relatively long wavelength. Rati Langley method (RLM): RLM calculates the calibration coefficient at another reference wavelength I proposed a calibration method that improves calibration accuracy in all wavelength bands by utilizing the fact that the calibration coefficient of an arbitrary wavelength can be estimated. Specifically, calibration coefficients of other wavelengths were estimated from the calibration coefficient by ILM at $0.87 \mu \mathrm{m}$ by the RLM method. The calibration error of the proposed method was intentionally evaluated by numerical simulation based on actual measurement data when the measurement error of $\pm 3 \%$ and $\pm 5 \%$ was superimposed on the measurement value of the marginal light, and the maximum of the error was 0.0014 and 0.0428 , and those of ILM were 0.011 and 0.0489 . Therefore, the proposed calibration method is more robust to measurement error than ILM, and it was found that highly accurate calibration is possible over all wavelengths

The accuracy of the proofreading method was evaluated based on the standard deviation of the calibration coefficient based on the measured data of the Sky-radiometer for 15 days, which is suitable for calibration, out of the measured data over 4 years, it was 0.02016 , and the calibration coefficient by ILM. The standard deviation of 0.03858 of the proof calibration method was confirmed.

Further experimental study is required for validation of the proposed method.

\section{ACKNOWLEDGMENT}

The author would like to thank Dr. Teruyuki Nakajima of JAXA and Dr. Xing Ming Liang of NOAA/NESDIS for their valuable comments and suggestions. Also, author would like to thank the fourth group members of the Department of Information Science, Saga University for their contribution to the experiments.

\section{REFERENCES}

[1] Kohei Arai, Akira Makoto, Simultaneous estimation of the complex refractive index and particle size distribution of aerosol using scattering and marginal light by simulated annealing, Journal of Japan Remote Sensing Society, Vol. 23, No. 1, .11-20, 2003.

[2] Shaw, G.E., Solar spectral irradiance and atmospheric transmission at Mauna Loa Observatory. Appl. Opt., 21, 2007_2011. 1982.

[3] Holben, B.N., and Coauthors, AERONET-A federated instrument network and data archive for aerosol characterization. Remote Sens. Environ., 66, 1_16. 1998.

[4] McArthur, L.J.B., D.H. Halliwell, O.J. Neibergall, N.T. O'Neill, J.R. Slusser, and C. Wehrli, Field comparison of network sun photometers., J. Geophys. Res., 108, 4596, doi:10.1029/2002JD002964. 2003.

[5] Kohei Arai, Self-Studied Remote Sensing, Mori Kita Publication 2004

[6] Langley, S.P., The bolometer and radiant energy. Proc. Amer. Acad. Arts Sci., 16, 342. 1881.

[7] Schmid, B., and C. Wehrli, Comparison of sun photometer calibration by use of the Langley technique and the standard lamp. Appl. Opt., 34, 4500_4512. 1995.

[8] Slusser, J.R., J.H. Gibson, D.S. Bigelow, D. Kolinski, P. Dister-hoft, K. Lantz, and A. Beaubien, Langley method of calibrating UV filter radiometers. J. Geophys. Res., 105, 4841_4849. 2000. 
[9] Adler-Golden, S.M., J.R.Slusser, Comparison of Plotting Methods for Solar Radiometer Calibration J. Atmospheric and Oceanic Technology, 24, 935-938, American Meteorological Society, 2007.

[10] Forgan, B.W., General method for calibrating sun photometers. Appl. Opt., 33, 4841-4850, 1994.

[11] Namajima, T., Tonna, G., Rao, R. et al. Use of sky brightness measurements from ground for remote sensing of particulate polydispersions. Appl. Opt. 35, 2672-2686, 1996.

[12] Tanaka, M., Nakajima, T., Shiobara, M., Calibration of a sunphotometer by simultaneous measurements of direct-solar and circumsolar radiations. Appl. Opt., 25, 1170-1176, 1986.

[13] Schotland, R.M., Lea, T.K., Bais in a solar constant determination by the Langley method due to structured atmospheric aerosol. Appl. Opt., 25, 2486-2491, 1986.

[14] Harrison, L., J. Michalsky, and J. Berndt, Automated multi-filter rotating shadowband radiometer: An instrument for optical depth and radiation measurements. Appl. Opt., 33, 5118_5125. 1994.

[15] Rochford, P.A., and Coauthors, Validation and refinement of hyperspectral/multispectral atmospheric compensation using shadowband radiometers. IEEE Trans. Geosci. Remote Sens., 43, 2898_2907. 2005.

[16] Shaw, G.E., Error analysis of multi-wavelength sunphotometry. Pure Appl. Geophys., 114, 1, 1976.
[17] Kohei Arai, Method for aureole estimation refinement through comparisons between observed aureole and estimated aureole based on Monte Carlo Ray Tracing, International Journal of Advanced Research in Artificial Intelligence, 2, 12, 1-8, 2013.

\section{AUTHOR's PROFILE}

Kohei Arai, He received BS, MS and PhD degrees in 1972, 1974 and 1982, respectively. He was with The Institute for Industrial Science and Technology of the University of Tokyo from April 1974 to December 1978 also was with National Space Development Agency of Japan from January, 1979 to March, 1990. During from 1985 to 1987, he was with Canada Centre for Remote Sensing as a Post-Doctoral Fellow of National Science and Engineering Research Council of Canada. He moved to Saga University as a Professor in Department of Information Science on April 1990. He was a counselor for the Aeronautics and Space related to the Technology Committee of the Ministry of Science and Technology during from 1998 to 2000. He was a councilor of Saga University for 2002 and 2003. He also was an executive councilor for the Remote Sensing Society of Japan for 2003 to 2005. He is an Adjunct Professor of University of Arizona, USA since 1998. He also is Vice Chairman of the Science Commission "A" of ICSU/COSPAR since 2008 then he is now award committee member of ICSU/COSPAR. He wrote 37 books and published 570 journal papers. He received 30 of awards including ICSU/COSPAR Vikram Sarabhai Medal in 2016, and Science award of Ministry of Mister of Education of Japan in 2015. He is now Editor-in-Chief of IJACSA and IJISA. http://teagis.ip.is.saga-u.ac.jp/index.ht 